Check for updates

Cite this: J. Mater. Chem. C, 2021 , 9, 5662

Received 6th December 2020, Accepted 26th March 2021

DOI: $10.1039 / d 0 t c 05727 d$

rsc.li/materials-c

\section{Transformation of $\mathrm{CO}_{3} \mathrm{O}_{4}$ nanoparticles to $\mathrm{CoO}$ monitored by in situ TEM and predicted ferromagnetism at the $\mathrm{CO}_{3} \mathrm{O}_{4} / \mathrm{CoO}$ interface from first principles $\dagger$}

\author{
Xiaodan Chen, (D) $\ddagger^{a}$ Heleen van Gog $\left(\mathbb{D} \ddagger^{*^{b}}\right.$ and Marijn A. van Huis (D) *a
}

\begin{abstract}
Nanoparticles of $\mathrm{CO}_{3} \mathrm{O}_{4}$ and $\mathrm{CoO}$ are of paramount importance because of their chemical properties propelling their applications in catalysis and battery materials, and because of their intriguing magnetic properties. Here we elucidate the transformation of $\mathrm{CO}_{3} \mathrm{O}_{4}$ nanoparticles to $\mathrm{CoO}$ into nanoscale detail by in situ heating in the transmission electron microscope (TEM), and we decipher the energetics and magnetic properties of the $\mathrm{CO}_{3} \mathrm{O}_{4} / \mathrm{CoO}$ interface from first principles calculations. The transformation was found to start at a temperature of $350{ }^{\circ} \mathrm{C}$, and full conversion of all particles was achieved after heating to $400{ }^{\circ} \mathrm{C}$ for 10 minutes. The transformation progressed from the surface to the center of the nanoparticles under the formation of dislocations, while the two phases maintained a cube-on-cube orientation relationship. Various possibilities for magnetic ordering were considered in the density functional theory (DFT) calculations and a favorable $\mathrm{CO}_{3} \mathrm{O}_{4} / \mathrm{CoO}\{100\} /\{100\}$ interface energy of $0.38 \mathrm{~J} \mathrm{~m}^{-2}$ is predicted for the lowest-energy ordering. Remarkably, the DFT calculations revealed a substantial net ferromagnetic moment originating from the interface between the two antiferromagnetic compounds, amounting to approximately $13.9 \mu_{\mathrm{B}} \mathrm{nm}^{-2}$. The transformation was reproduced ex situ when heating at a temperature of $400{ }^{\circ} \mathrm{C}$ in a high vacuum chamber.
\end{abstract}

\section{Introduction}

$\mathrm{Co}_{3} \mathrm{O}_{4}$ nanocrystals are materials of great importance to many applications. Cobalt oxide nanoparticles and their reduced derivatives are used as catalysts in the well-known FischerTropsch process for the production of hydrocarbon fuels, but are also considered as catalysts for water splitting. ${ }^{1-4}$ Furthermore, cobalt oxide is one of the most frequently used materials in Li-ion batteries ${ }^{5,6}$ powering cell phones and other electronic equipment, and is used in gas sensors as well. ${ }^{7}$ Understanding the reduction process and its mechanism at the nanoscale is essential for controlling the nanoparticle properties in these applications. The reduction of $\mathrm{Co}_{3} \mathrm{O}_{4}$ under different chemical and physical conditions has been extensively investigated, as will be discussed in more detail below. A two-stage reduction

\footnotetext{
${ }^{a}$ Soft Condensed Matter, Debye Institute for Nanomaterials Science, Utrecht University, Princetonplein 5, 3584 CC Utrecht, The Netherlands. E-mail:m.a.vanhuis@uu.nl

${ }^{b}$ Engineering Thermodynamics, Process \& Energy Department, Faculty of Mechanical, Maritime and Materials Engineering, Delft University of Technology, Leeghwaterstraat 39,2628 CB Delft, The Netherlands.E-mail: h.vangog@tudelft.nl $\dagger$ Electronic supplementary information (ESI) available. See DOI: 10.1039/ d0tc05727d

\# These authors contributed equally.
}

process has been reported by many researchers, ${ }^{8-10}$ where spinel $\mathrm{Co}_{3} \mathrm{O}_{4}$ first transforms to rock salt $\mathrm{CoO}$ and subsequently to elemental Co,

$$
\mathrm{Co}_{3} \mathrm{O}_{4} \rightarrow \mathrm{CoO} \rightarrow \mathrm{Co} .
$$

Elemental Co adopts the hexagonal close packed (hcp) crystal structure in the bulk phase, but adopts the face centered cubic (fcc) structure with a lattice parameter of $0.354 \mathrm{~nm}$ when the particle size is less than $30 \mathrm{~nm} .{ }^{11}$ The crystal structures of $\mathrm{Co}_{3} \mathrm{O}_{4}$ and $\mathrm{CoO}$ are both cubic and the lattice parameter of $\mathrm{Co}_{3} \mathrm{O}_{4}$ is approximately twice as large as the lattice parameter of $\mathrm{CoO}$.

Fig. 1 shows their schematic structure. $\mathrm{Co}_{3} \mathrm{O}_{4}$ has the spinel crystal structure. Cobalt atoms are in the interstices of the distorted fcc lattice of oxygen atoms. $\mathrm{Co}^{2+}$ cations occupy tetrahedral interstitial sites and $\mathrm{Co}^{3+}$ cations occupy octahedral interstitial sites. In contrast, $\mathrm{CoO}$ has a rock salt structure with $\mathrm{Co}^{2+}$ cations on one of the interpenetrating fcc sublattices and $\mathrm{O}^{2-}$ anions on the other fcc sublattice.

The thermal stability of the Co-O system has been investigated in several ways. The thermodynamic properties of both solid and liquid phases of the Co-O system were calculated by Chen et al. ${ }^{12}$ In a study employing interatomic potentials obtained by machine 
(a)

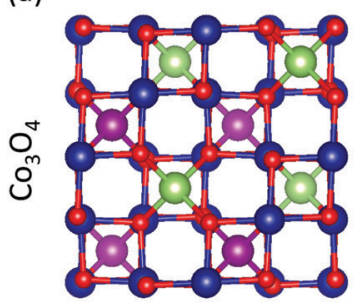

(d)

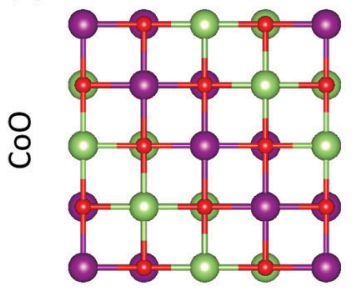

(b)

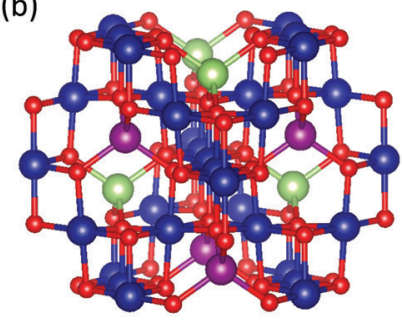

(e)

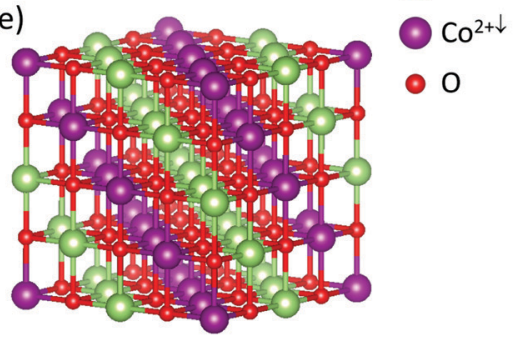

(c)

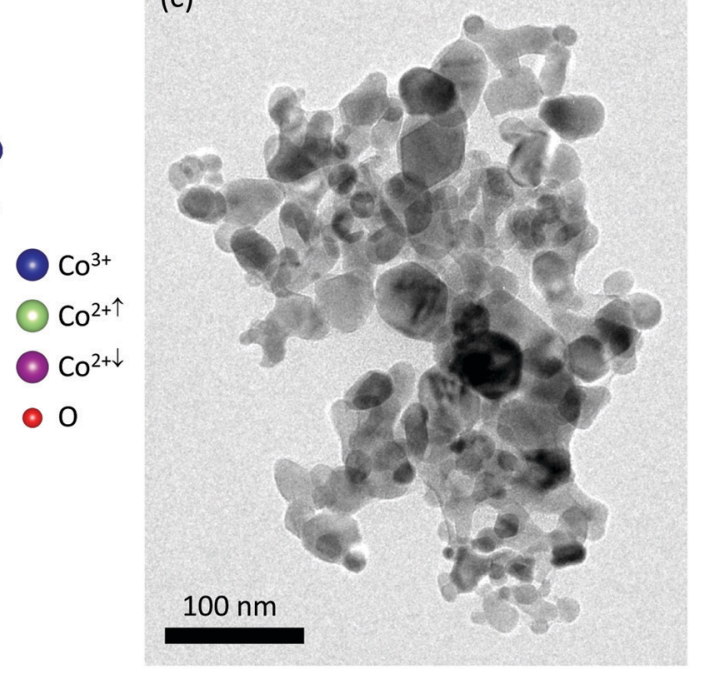

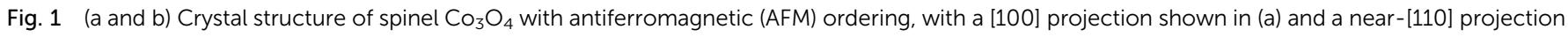

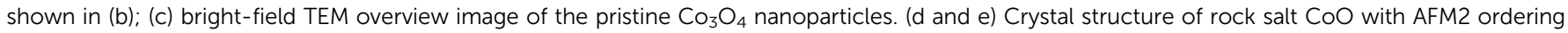

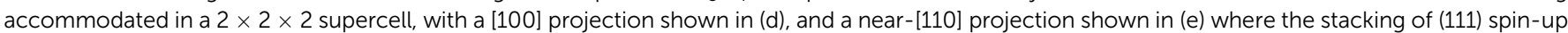

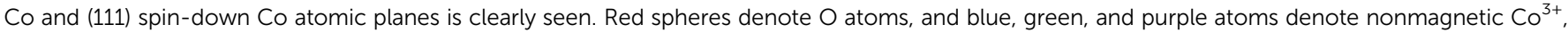
spin-up $\mathrm{Co}^{2+}$, and spin-down $\mathrm{Co}^{2+}$ atoms, respectively.

learning, Kong et al. showed that only $\mathrm{CoO}$ and $\mathrm{Co}_{3} \mathrm{O}_{4}$ are stable compositions in the Co-O system and that the transition between cubic $\mathrm{CoO}$ and $\mathrm{Co}_{3} \mathrm{O}_{4}$ is reversible. ${ }^{13}$ Navrotsky et al. calculated phase diagrams for both the bulk $\mathrm{Co}-\mathrm{O}$ system and the nanoscale Co-O system, and showed that the range where the CoO phase is stable (in terms of partial oxygen pressure and temperature) is considerably narrower for $10 \mathrm{~nm}$ sized nanoparticles in comparison with the $\mathrm{CoO}$ range of stability in the bulk phase diagram. ${ }^{14}$

The reduction processes have been investigated experimentally under a $\mathrm{H}_{2}$ atmosphere ${ }^{4,8,10,15,16}$ and under plasma exposure. ${ }^{17}$ Ward et al. observed the reduction using environmental transmission electron microscopy (ETEM) under low hydrogen pressures, and found that $\mathrm{Co}_{3} \mathrm{O}_{4}$ nanoparticles reduced to $\mathrm{CoO}$ predominantly at a temperature of $350{ }^{\circ} \mathrm{C}$ and at a hydrogen pressure of 0.1 mbar $(10 \mathrm{~Pa})$, while the formation of pure Co was only observed upon further heating at $450{ }^{\circ} \mathrm{C}$ at a higher hydrogen pressure of $0.3 \mathrm{mbar}(30 \mathrm{~Pa}) .{ }^{18}$ Bulavchenko et al. investigated the transformation at standard pressure $\left(1.0 \times 10^{5} \mathrm{~Pa}\right)$ using X-ray diffraction (XRD) and reported the two-stage process, but in addition they also reported a one-step process where the $\mathrm{Co}_{3} \mathrm{O}_{4}$ particles could be reduced directly to metallic Co, without intermediate formation of $\mathrm{CoO}$, when the samples were exposed to pure $\mathrm{H}_{2}{ }^{9}$ The standard enthalpy of reduction of $\mathrm{Co}_{3} \mathrm{O}_{4}$ to $\mathrm{CoO}$ was reviewed and investigated experimentally by Mayer et al. ${ }^{19}$ A detailed high-resolution study of the nanoscale structural transformation during heating under vacuum conditions in the absence of any reducing agents has not yet been performed, though. The rapidly developing in situ transmission electron microscopy (TEM) technique now enables the direct observation of phase transformations at atomic resolution, ${ }^{20}$ which greatly benefits a detailed investigation of the reduction process.
The $\mathrm{Co}_{3} \mathrm{O}_{4}$ and $\mathrm{CoO}$ phases have also been extensively studied because of their interesting electronic and magnetic structures, which have been the subject of a lively debate in the literature. ${ }^{21-25}$ The rock salt CoO phase undergoes a Jahn-Teller distortion at low temperature, rendering it a monoclinic phase that is still pseudo-rock-salt type. ${ }^{23}$ The magnetic ground state is antiferromagnetic (AFM), where spins of equal sign are arranged in the cubic (111) planes of Co atoms, and the spin-up/spindown alternation is along the [111] stacking direction of these Co atomic planes. This AFM type is referred to as AFM2. ${ }^{22}$ The magnetic moment of the $\mathrm{Co}^{2+}$ atoms is approximately $3 \mu_{\mathrm{B}}{ }^{21,22}$ and the Néel temperature is $T_{\mathrm{N}}=287 \mathrm{~K}^{21,26}$ The material is a semiconductor both below and above that temperature; reported values for the band gap are about $2.5-2.7 \mathrm{eV}^{23,27}$

In the spinel-type $\mathrm{Co}_{3} \mathrm{O}_{4}$ phase the trivalent $\mathrm{Co}^{3+}$ ions are nonmagnetic while the $\mathrm{Co}^{2+}$ ions carry a magnetic moment. At low temperature the $\mathrm{Co}_{3} \mathrm{O}_{4}$ phase is antiferromagnetic (AFM) with the $\mathrm{Co}^{2+}$ ions following conventional AFM ordering with alternating magnetic moments along the cubic axes (AFM1 ordering). The experimentally determined magnetic moment of the $\mathrm{Co}^{2+}$ ions is $3.26 \mu_{\mathrm{B}}$ and the Néel temperature is $T_{\mathrm{N}}=40 \mathrm{~K}^{24}$ $\mathrm{Co}_{3} \mathrm{O}_{4}$ is a semiconductor, with reported values for the band gap varying from $0.74 \mathrm{eV}$ (ref. 25) to $1.5-2.5 \mathrm{eV}^{24,28}$

The electronic and magnetic properties of $\mathrm{CoO}$ and $\mathrm{Co}_{3} \mathrm{O}_{4}$ nanoscale particles can differ dramatically from the properties discussed above for $\mathrm{CoO}$ and $\mathrm{Co}_{3} \mathrm{O}_{4}$ bulk compounds. That the Néel temperature of both bulk compounds is below room temperature while our experiments are performed at room temperature, does not necessarily imply that the nanoparticles under investigation in the present study will not be magnetic. In general, due to finite size effects, and surface and interface effects, the 
magnetization and magnetic anisotropy of nanoparticles can be much larger than the magnetization and magnetic anisotropy of their bulk counterparts, and the Curie and Néel temperatures can vary by hundreds of degrees. ${ }^{29}$ Typically, magnetic nanoparticles consist of only one magnetic domain, which explains their generally higher anisotropy in comparison with multi-domain bulk structures. Furthermore, below a critical size nanoparticles can become superparamagnetic, in which case the atomic magnetic moments in the nanoparticles will be continuously fluctuating when an external magnetic field is absent but respond with high levels of magnetization when an auxiliary magnetic field is applied. $^{29}$ The magnetic ordering temperature of a nanomaterial is generally lower than the bulk phase value, but this effect can be masked or reversed by crystallographic parameters or composition. ${ }^{29}$ For $\mathrm{CoO}$ and $\mathrm{Co}_{3} \mathrm{O}_{4}$ nanoparticles, a reduction of the Néel temperature was observed; this reduction has been found to increase with decreasing particle size. ${ }^{30-32}$ At the same time, the literature on $\mathrm{CoO}$ and $\mathrm{Co}_{3} \mathrm{O}_{4}$ nanoparticles reports the observation of net ferromagnetism at room temperature; ${ }^{32-35}$ this net-ferromagnetic effect is generally attributed to surface effects. Room-temperature ferromagnetism has also been reported for $\mathrm{Co}_{3} \mathrm{O}_{4} / \mathrm{CoO}$ core/shell particles; in their case, the net-ferromagnetism was attributed to interface effects. $^{36}$

The experiments performed in this work established that the $\mathrm{Co}_{3} \mathrm{O}_{4}$ and $\mathrm{CoO}$ phases are in a cube-on-cube orientation relationship with respect to each other. We therefore employed density functional theory (DFT) calculations to investigate the $\{100\} /\{100\}$ interface between the two phases. This particular interface orientation is observed in $\mathrm{Co}_{3} \mathrm{O}_{4} / \mathrm{CoO}$ nanocrystals in the present study, and was also described experimentally by Tung et al. in $\mathrm{Co}_{3} \mathrm{O}_{4} / \mathrm{CoO}$ core/shell nanocubes. ${ }^{37}$ Various possible input magnetic configurations were considered for the DFT calculations. The interface energy of the lowest-energy $\{100\} /\{100\}$ interface between the $\mathrm{Co}_{3} \mathrm{O}_{4}$ and $\mathrm{CoO}$ phase was calculated. We also aim to answer the interesting question of whether the overall magnetism and the magnetic ordering changes when the two phases are brought into contact with each other.

In the present study, we first investigate the thermal reduction of $\mathrm{Co}_{3} \mathrm{O}_{4}$ to $\mathrm{CoO}$ nanocrystals experimentally by means of in situ vacuum heating in the TEM. The transformation was monitored both by real-space imaging and by electron diffraction (ED) to identify the formation of new phases and their crystal structures. The reduction started at a temperature of $350{ }^{\circ} \mathrm{C}$, and full reduction of all particles was achieved at $400{ }^{\circ} \mathrm{C}$. During the transition, the two phases were found to be in a cube-on-cube orientation relationship. Next, the interface between $\mathrm{Co}_{3} \mathrm{O}_{4}$ and $\mathrm{CoO}$ is investigated by means of DFT calculations, to calculate the interface energy of the interface and to study the effect of the interface on the magnetic properties of the multiphase configuration.

\section{Experimental section}

\section{Sample preparation and TEM characterization}

The $\mathrm{Co}_{3} \mathrm{O}_{4}$ nanocrystals (NCs) were purchased from SigmaAldrich and had a broad size distribution of 5-50 $\mathrm{nm}$ as shown in Fig. 1(c). The Electron Diffraction (ED) and in situ TEM investigations were conducted using a TFS TalosF200X TEM operating at $200 \mathrm{kV}$ with a point-to-point resolution of approximately $1.1 \AA$ in bright-field TEM imaging mode. An overview TEM image of the pristine samples is shown in Fig. 1(c). Highresolution imaging was also conducted with a double aberration corrected TFS Spectra300 TEM, operated at $300 \mathrm{kV}$ and with a point-to-point resolution of $50 \mathrm{pm}$ in TEM mode, on partially transformed particles to show high resolution details of the heterogeneous nanostructures. The TEM specimens were prepared by drop casting the $\mathrm{Co}_{3} \mathrm{O}_{4}$ solution onto a DENSsolutions MEMS heating chip containing electron-transparent $15 \mathrm{~nm}$ thick SiN membranes, which we will refer to as the 'windows' on the chip.

\section{X-ray diffraction (XRD)}

The crystal structure of $\mathrm{Co}_{3} \mathrm{O}_{4}$ in the pristine samples was confirmed by XRD measurements (shown in Fig. S1, ESI $\dagger$ ). The XRD was conducted using a PW 1729 Philips diffractometer, equipped with a $\mathrm{Cu} \mathrm{K}_{\alpha}$ X-ray source (1.79026 ̊). The $\mathrm{Co}_{3} \mathrm{O}_{4}$ powder was uniformly dispersed on an aluminum substrate for the XRD measurement.

\section{In situ TEM heating}

The heating chips were subsequently mounted on a DENSsolutions single tilt heating holder. The $\mathrm{Co}_{3} \mathrm{O}_{4}$ nanocrystals were first heated from room temperature to $900{ }^{\circ} \mathrm{C}$ with $50{ }^{\circ} \mathrm{C}$ increments to monitor their evolution with temperature. It was established that reduction took place at $350-400{ }^{\circ} \mathrm{C}$. The transformation took place everywhere, also in areas on the heating chip that were not previously exposed to the electron beam. A control experiment was also performed where the NCs were heated to $400{ }^{\circ} \mathrm{C}$ and then cooled down gradually, to verify that the NCs did not transform into a structure other than $\mathrm{CoO}$ rocksalt after cooling to room temperature, which was not the case.

\section{Ex situ heating experiments}

Several ex situ control experiments were performed. Ex situ heating experiments were conducted in tube furnaces under air flow, $\mathrm{N}_{2}$ flow, and under vacuum. For these experiments, the complete heating chips with the sample, prepared in the same way as for the in situ heating experiments, were inserted in the oven. The samples heated under air and under $\mathrm{N}_{2}$ flow were heated at a rate of $5{ }^{\circ} \mathrm{C} \mathrm{min}^{-1}$. The samples were kept at $400{ }^{\circ} \mathrm{C}$ for 10 minutes and allowed to cool down naturally to room temperature. The samples were also heated with the heating holder in air, and with the heating holder inserted in a high vacuum chamber (Gatan pumping station Model 655), applying the same rate as in the in situ heating experiments. The pressure in the high vacuum chamber was approximately $1.0 \times 10^{-7}$ Torr. After holding the temperature at $400{ }^{\circ} \mathrm{C}$ for 10 minutes, the sample was cooled down fast to room temperature and swiftly inserted in the TEM for subsequent analysis. 


\section{Computational section}

Density functional theory (DFT) calculations were employed to study the $\mathrm{CoO} / \mathrm{Co}_{3} \mathrm{O}_{4}\{100\} /\{100\}$ interface. First, the $\mathrm{CoO}$ and $\mathrm{Co}_{3} \mathrm{O}_{4}$ bulk phases were calculated separately, to obtain bulk phase reference energies and equilibrium lattice parameters, and to establish the magnetic ground state of the bulk phases. Four multiphase supercells with various magnetic orderings for the constituent bulk phase slabs were then constructed to calculate the interface energy of four different magnetic configurations. A Bader analysis ${ }^{38}$ was performed to investigate if, and how, the magnetism changes when the two phases are brought into contact.

\section{Computational method}

The calculations were performed using the plane-wave VASP $\operatorname{code}^{39,40}$ employing the projector augmented wave (PAW) scheme ${ }^{41,42}$ and the generalized gradient approximation (GGA) with the exchange-correlation functional by Perdew, Burke and Ernzerhof (PBE) ${ }^{43}$ For the bulk phases, the DFT $+U$ approach ${ }^{44}$ was considered as well. In the DFT $+U$ approach, the Hubbard $U$ potential has the effect of lowering the energies of the $\mathrm{d}$ electron bands and as such compensates for the deficiency of standard DFT in describing strongly correlated systems. The use of hybrid functionals such as HSE06 or PBE0 was not considered as these methods are computationally prohibitively expensive for the large interface supercells considered in this work. The energy cutoff and the density of the $k$-meshes were tested to ensure energy convergence well within $2 \mathrm{meV}$ per atom. All calculations were performed in reciprocal space as calculations in real space were often found not to converge properly electronically. The required cutoff energy of the wave functions found from the energy convergence tests was $700 \mathrm{eV}$, which is higher than the energy cutoffs typically reported in the literature (500-600 eV). A cutoff energy of $980 \mathrm{eV}$ was used for the augmentation functions. The electronic wave functions were sampled using the Monkhorst and Pack scheme, ${ }^{45}$ on $6 \times 6 \times 6 k$-grids for both the conventional $\mathrm{Co}_{3} \mathrm{O}_{4}$ unit cell and the $2 \times 2 \times 2$ supercell of the conventional $\mathrm{CoO}$ unit cell that is required to accommodate the AFM2 magnetic ordering of the latter (see Fig. $1(\mathrm{~d}$ and e)). For the interface supercells, $6 \times 6 \times 1 \mathrm{k}$-grids were used.

All simulation cells were structurally optimized, relaxing atomic positions and lattice parameters, to yield lower-energy configurations. For the ionic relaxation loop, accumulative energy and atomic force convergence criteria of $10^{-5} \mathrm{eV}$ and $0.01 \mathrm{eV} \AA^{-1}$, respectively, were applied for the bulk phase calculations; for the interface calculations, accumulative criteria of $10^{-4} \mathrm{eV}$ and $0.01 \mathrm{eV}^{-1}$ were used. For all calculations, an energy convergence criterion of $10^{-6} \mathrm{eV}$ was set for the electronic convergence loop. For the spin-polarized calculations, the initial magnitude of the magnetic moment was always set to $4 \mu_{\mathrm{B}}$ for the atoms carrying a magnetic moment (i.e., for all $\mathrm{Co}^{2+}$ atoms), and to 0 for all other atoms. The magnetic moments were not fixed but allowed to relax (to reduce in magnitude, and even to change in sign) during the electronic self-consistent calculation. The Bader analysis, performed to determine the charge distribution among the atoms and to calculate the magnetic moments on the atoms, was carried out using the approach by Henkelman et al. ${ }^{46}$ All calculations are valid for a temperature of $0 \mathrm{~K}$ and a pressure of 0 Pa. Zero-point vibration contributions have been neglected. Non-collinear magnetism has not been considered.

\section{$\mathrm{CoO}$ and $\mathrm{Co}_{3} \mathrm{O}_{4}$ reference phases}

Most DFT calculations in the literature have been performed using the primitive cells of the cubic phases of $\mathrm{CoO}$ and $\mathrm{Co}_{3} \mathrm{O}_{4}$, while Dalverny et al. performed calculations on the Jahn-Teller distorted monoclinic phase of $\mathrm{CoO} .{ }^{23}$ In the present work, we performed calculations and parameter testing on the conventional unit cells as these are more representative for the interface supercells we wish to construct. For the CoO phase, input configurations with antiferromagnetic AFM1 and AFM2, ferromagnetic (FM), and nonmagnetic (NM) magnetic orderings were considered. Here, AFM1 represents the alternation of spin-up and spin-down Co (100) planes, whereas AFM2 represents the alternation of spin-up/spin-down Co (111) atomic planes as depicted in Fig. 1(d and e); we here follow the nomenclature by Deng et al. ${ }^{22}$ For the $\mathrm{Co}_{3} \mathrm{O}_{4}$ phase, AFM1 (as depicted in Fig. 1(a and b)), FM, and NM magnetic orderings were considered as input. All configurations were calculated both with standard DFT, i.e., using the GGA-PBE exchangecorrelation functional, and with $\mathrm{DFT}+U$. In the literature reporting $\mathrm{DFT}+U$ results on $\mathrm{CoO}$ and $\mathrm{Co}_{3} \mathrm{O}_{4}$ phases, in general $U_{\text {eff }}$ values between 4 and $5 \mathrm{eV}$ are chosen. ${ }^{21-25}$ Here, for our $\mathrm{DFT}+U$ calculations, we used an identical value of $U_{\text {eff }}=4.4 \mathrm{eV}$ for all Co atoms in the two compounds, as we wish not to distinguish between $\mathrm{Co}^{2+}$ and $\mathrm{Co}^{3+}$ when interfaces are created.

\section{$\mathrm{CoO} / \mathrm{Co}_{3} \mathrm{O}_{4}$ supercells and interface energy}

Fig. 2 shows the interface supercells with the various configurations of the magnetic orderings that were used as input for the calculations. The designation of the magnetic orderings applies to the $\mathrm{CoO} / \mathrm{Co}_{3} \mathrm{O}_{4}\{100\} /\{100\}$ interface simulated by a supercell of which the bottom half consists of a $2 \times 2 \times 4$ supercell of the conventional $\mathrm{CoO}$ unit cell and the top half consists of a $1 \times 1 \times 2$ supercell of the conventional $\mathrm{Co}_{3} \mathrm{O}_{4}$ unit cell, adding up to a total of 240 atoms per interface supercell. Besides a fully nonmagnetic (NM/NM) and a fully ferromagnetic (FM/FM) input configuration, two antiferromagnetic input configurations were considered. In the antiferromagnetic configurations, the interface is formed by a bottom $\mathrm{CoO}$ slab that has either AFM1 or AFM2 ordering and a top $\mathrm{Co}_{3} \mathrm{O}_{4}$ slab that is always AFM1 ordered, which results in the AFM1/AFM1 and AFM2/AFM1 configurations depicted in Fig. 2(c)-(e).

After full relaxation of the supercells, the interface energy $\gamma_{\text {int }}$ was calculated for each of the interfaces as:

$$
\gamma_{\text {int }}=\frac{E_{\text {int }}^{\text {super }}-n E_{\mathrm{CoO}}-m E_{\mathrm{Co}_{3} \mathrm{O}_{4}}}{2 A_{\text {int }}}
$$

Here, $E_{\text {int }}^{\text {super }}$ is the energy of the interface supercell; $E_{\mathrm{CoO}}$ and $E_{\mathrm{CO}_{3} \mathrm{O}_{4}}$ are the energy of one reference unit cell of $\mathrm{CoO}$ and $\mathrm{Co}_{3} \mathrm{O}_{4}$, respectively; $n$ and $m$ are the number of $\mathrm{CoO}$ and $\mathrm{Co}_{3} \mathrm{O}_{4}$ unit cells in the supercell; and $A_{\text {int }}$ is the area of the interface, 
NM/NM

(a)

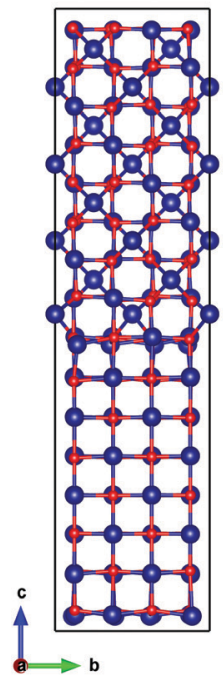

FM/FM

(b)

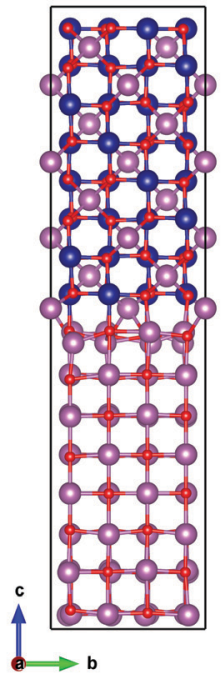

AFM1/AFM1

(c)

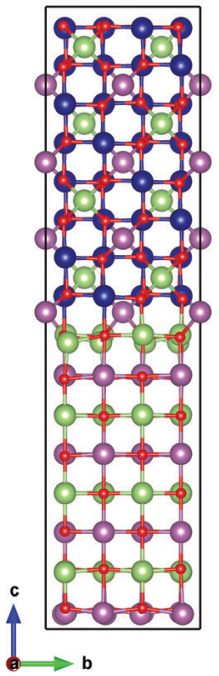

AFM2/AFM1

(d)

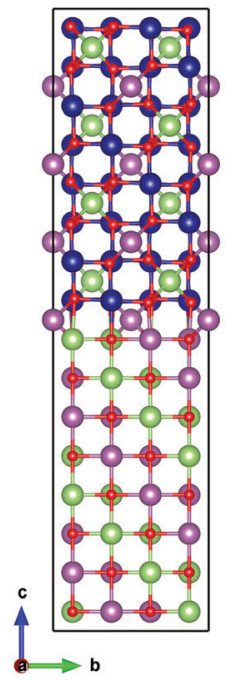

(e)

Fig. 2 Atomic models of the interface supercells with various magnetic orderings. Panels (d) and (e) both illustrate the AFM2/AFM1 configuration, showing a [100] projection in (d) and a [110] projection in (e). Panel (e) is included so that the AFM2 ordering in the CoO phase, i.e, the antiferromagnetic ordering along the $\langle 111\rangle$ direction, can be nicely seen. Red spheres denote $\mathrm{O}$ ions. Blue spheres denote nonmagnetic $\mathrm{Co}^{3+}$ ions. Purple and light green spheres denote spin-up $\mathrm{Co}^{2+}$ and spin-down $\mathrm{Co}^{2+}$ ions, respectively.

calculated from the supercell lattice vectors as $A_{\text {int }}=|a \times b|$. The factor of 2 in the denominator arises from the fact that due to the periodic boundary conditions that apply to plane-wave DFT calculations, the periodic interface supercells always contain two interfaces.

\section{Results and discussion}

\section{In situ and ex situ TEM investigations}

The in situ heating experiments conducted on the $\mathrm{Co}_{3} \mathrm{O}_{4} \mathrm{NCs}$ were performed as described in the Experimental section. An XRD spectrum confirming the $\mathrm{Co}_{3} \mathrm{O}_{4}$ phase of the pristine nanosamples can be found in Fig. S1 of the ESI. $\dagger$ First, the particles as dropcast on the heating chip were heated from room temperature to $900{ }^{\circ} \mathrm{C}$ with increments of $50{ }^{\circ} \mathrm{C}$. Brightfield TEM images and selected area electron diffraction (SAED) patterns were recorded at every heating step. Fig. 3 shows TEM images of the cobalt oxide nanoparticles in two different areas at room temperature, at $400{ }^{\circ} \mathrm{C}$, and at $800{ }^{\circ} \mathrm{C}$. The particles agglomerated at room temperature after drying on the TEM supports. After heating at a temperature of $400{ }^{\circ} \mathrm{C}$, the surfaces of the nanocrystals became uneven and more faceted. This indicates that particular crystallographic facets are preferentially exposed, driven by minimization of the total surface energy. As the onset of faceting coincides with the transformation to $\mathrm{CoO}$, which will be become clear from the SAEDs in Fig. 4, this is possibly caused by CoO NPs having more distinct facet-dependent surface energies than $\mathrm{Co}_{3} \mathrm{O}_{4}$ NPs. In addition, stronger diffraction contrast also appeared on the particles, which we attribute to the phase transformation to $\mathrm{CoO}$ as also evidenced by the SAED results of Fig. 4 and Fig. S2 (ESI $\dagger$ ). At $800{ }^{\circ} \mathrm{C}$, the particles coalesced and fused as is clear from the bottom-right panel in Fig. 3, which corroborates of the results of the SAED patterns showing fewer but stronger peaks at temperatures of $600{ }^{\circ} \mathrm{C}$ and higher (Fig. S2 of the $\mathrm{ESI} \dagger)$.

While bright-field TEM imaging provides information about changes in morphology and in the size of the NCs, the SAED patterns uniquely identify the crystal structure of the NCs during the heating experiments. Fig. S2 of the ESI $\dagger$ shows the diffraction patterns (DPs) recorded during the whole heating process. At room temperature and after heating at temperatures of up to $300{ }^{\circ} \mathrm{C}$, the SAED patterns corresponded to the $\mathrm{Co}_{3} \mathrm{O}_{4}$ crystal structure. Upon annealing at $350{ }^{\circ} \mathrm{C}$, however, the patterns started to change, and after keeping the sample at $400{ }^{\circ} \mathrm{C}$ for 10 minutes, only three rings remained that are indicative of the highly symmetric $\mathrm{CoO}$ phase.

In Fig. 4, a comparison is shown between the SAED patterns at $20{ }^{\circ} \mathrm{C}$ (left) and at $400{ }^{\circ} \mathrm{C}$ (right). The rings in the DPs were indexed and found to correspond to the $\mathrm{Co}_{3} \mathrm{O}_{4}$ phase and to the $\mathrm{CoO}$ phase, respectively. Table $\mathrm{S} 2$ ( $\mathrm{ESI} \dagger$ ) shows the corresponding lattice spacings of the rings in both diffraction patterns. Fig. S3 $(\mathrm{ESI} \dagger)$ ) shows the integrated DPs at $20{ }^{\circ} \mathrm{C}, 350{ }^{\circ} \mathrm{C}, 400{ }^{\circ} \mathrm{C}$ and $400{ }^{\circ} \mathrm{C}$ after 10 minutes, clearly showing the transformation as well. From $350{ }^{\circ} \mathrm{C}$ onwards, peaks corresponding $\mathrm{Co}_{3} \mathrm{O}_{4}$ started to disappear or became weaker, whereas a new peak corresponding to the (002) reflection of $\mathrm{CoO}$ appeared. Finally at $400{ }^{\circ} \mathrm{C}$, only peaks corresponding to $\mathrm{CoO}$ were found, indicating that the transformation of the NPs was complete. Clearly, the SAED patterns show that the transformation to $\mathrm{CoO}$ took place from $350{ }^{\circ} \mathrm{C}$ onwards and was completed after heating to $400{ }^{\circ} \mathrm{C}$ for 

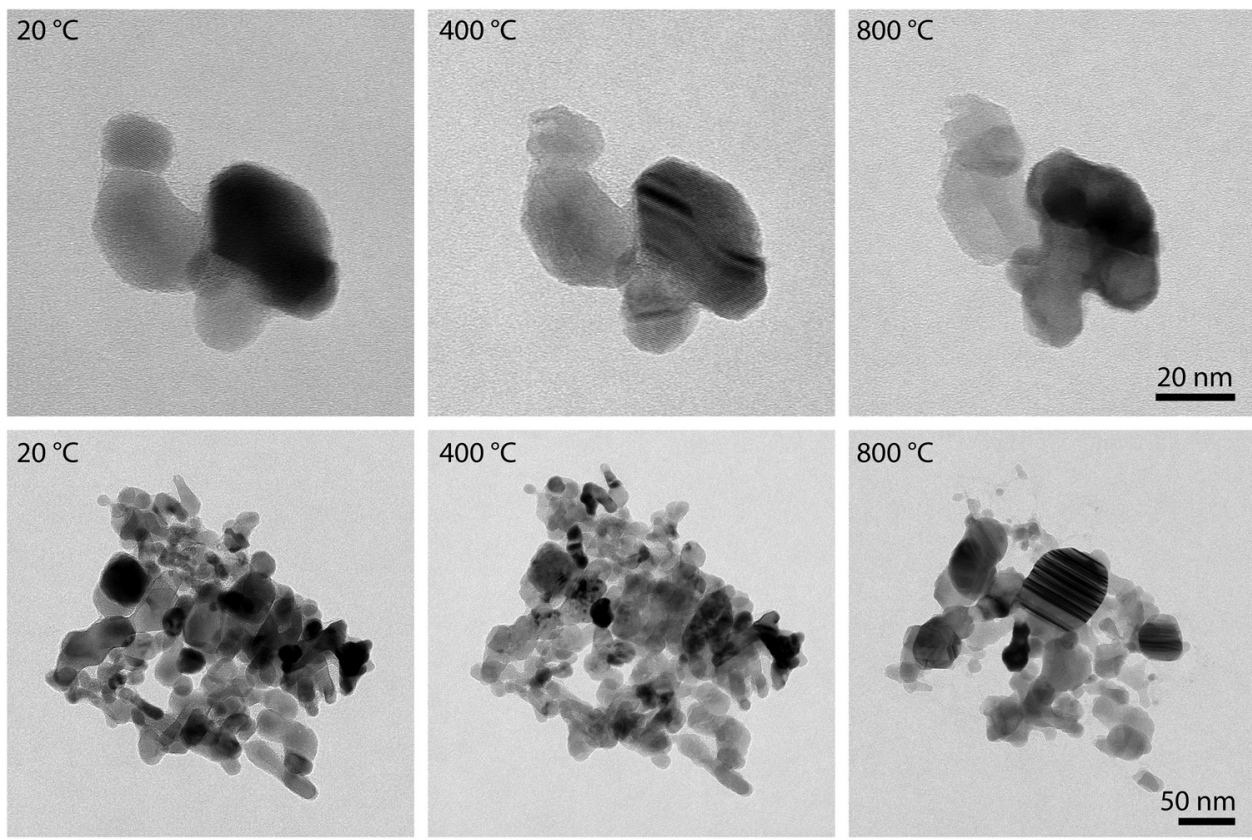

Fig. 3 Bright-field TEM images of (initially) $\mathrm{CO}_{3} \mathrm{O}_{4}$ NPs at room temperature, at $400{ }^{\circ} \mathrm{C}$ and at $800{ }^{\circ} \mathrm{C}$. The surfaces of the NPs become uneven at $400{ }^{\circ} \mathrm{C}$, while diffraction contrast increases.

10 minutes. Above $400{ }^{\circ} \mathrm{C}$, the rings in the DPs did not change any more, indicating no further reduction. From $600{ }^{\circ} \mathrm{C}$ onwards, there are fewer spots on the rings due to coalescence and alignment of the nanocrystals, which consequently became larger and fewer in number.
Four ex situ reference experiments were conducted for comparison with the in situ heating experiments. Ex situ heating was conducted in a tube oven in air (1), in a tube oven under $\mathrm{N}_{2}$ flow (2), using the heating holder while kept in ambient air outside the TEM (3), and using the heating holder in a high

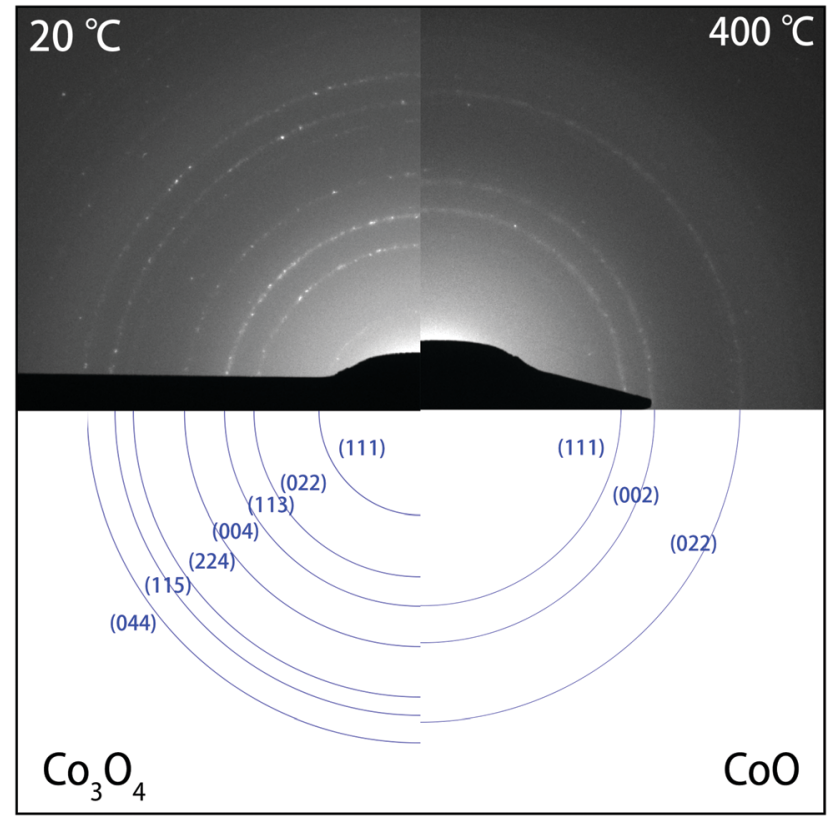

Fig. 4 SAED patterns (top) of $\mathrm{CO}_{3} \mathrm{O}_{4}$ NPs before heating at $20^{\circ} \mathrm{C}$ (left), and after heating for $10 \mathrm{~min}$ at $400{ }^{\circ} \mathrm{C}$ (right). At $20^{\circ} \mathrm{C}$, the diffraction rings in the DP corresponded to the $\mathrm{CO}_{3} \mathrm{O}_{4}$ phase. After heating at $400{ }^{\circ} \mathrm{C}$, only three rings remained that correspond to the highly symmetric CoO phase. The rings in the experimental SAED patterns (top) are indexed in blue (bottom). Please note that the $(h k l)$ indexing of the diffraction rings refers to reflections at $\{h k l\}$ families of lattice planes. The complete DPs are shown in Fig. S2 of the ESI. $\dagger$ 
vacuum chamber (4). The results are shown in Fig. S4 (ESI $\dagger$ ). The SAED patterns after heating in the vacuum chamber clearly indicate the CoO structure, showing that the phase transformation to $\mathrm{CoO}$ also took place ex situ under low pressure conditions. The SAED patterns after heating under standard pressure and under $\mathrm{N}_{2}$ flow still show the $\mathrm{Co}_{3} \mathrm{O}_{4}$ structure, i.e., the transformation did not take place under these ex situ conditions, which implies that the transformation from $\mathrm{Co}_{3} \mathrm{O}_{4}$ to $\mathrm{CoO}$ requires a very low partial oxygen pressure. The cooling processes in the microscope is typically much faster than in regular furnaces, so that high-temperature phases might be quenched to room temperature. As an additional control experiment, the NCs were heated in situ from $20{ }^{\circ} \mathrm{C}$ to $400{ }^{\circ} \mathrm{C}$ (transforming completely to $\mathrm{CoO}$ ) and subsequently cooled down very slowly to verify that no other structures than CoO are formed during cooling down. The resulting SAEDs are shown in Fig. S5 (ESI $\dagger$ ). Both diffraction patterns show a CoO rocksalt crystal structure. High resolution TEM images (shown in Fig. S6, ESI $\dagger$ ) also show that the particles remain in the $\mathrm{CoO}$ phase after heating and cooling down. Consequently, the transformation to $\mathrm{CoO}$ that is observed in situ must be caused by the combination of elevated temperature and the very low partial oxygen pressure under vacuum conditions.

The results of the ex situ experiments conducted in air and under nitrogen flow are in good agreement with the Co-O phase diagrams that Navrotsky et al. calculated for bulk and nanoscale cobalt oxide. ${ }^{14}$ For $10 \mathrm{~nm}$ sized anhydrous $\mathrm{Co}_{3} \mathrm{O}_{4}$ nanoparticles, these authors predicted that the partial oxygen pressure needs to be extremely low $\left(p\left(\mathrm{O}_{2} / 1 \mathrm{~atm}\right)<10^{-20}\right)$ for reduction to take place at a temperature of $650 \mathrm{~K}\left(\sim 350{ }^{\circ} \mathrm{C}\right)$. Consequently, during conditions of annealing ex situ at standard pressure either in air or under (not 100\% pure) nitrogen flow, the partial oxygen pressure will not be sufficiently low for the $\mathrm{Co}_{3} \mathrm{O}_{4}$ NPs to be reduced. The transformation was observed, though, during heating in the in situ experiments and when heating ex situ in the high vacuum chamber. The partial oxygen pressure in these high vacuum environments is unfortunately not known but must be considerably lower than the total pressure in the column of the TEM and in the vacuum chamber, which is approximately $1.0 \times 10^{-5} \mathrm{~Pa}$. Therefore, as the total partial pressure (with respect to atmospheric pressure) is $1.0 \times 10^{-10}$, the partial oxygen pressure will be considerably lower. The thermodynamic modelling as performed by Navrotsky et al. is only valid for systems in equilibrium, though. From a thermodynamic point of view, vacuum annealing in situ in the TEM or in a high vacuum chamber is always an out-ofequilibrium condition as oxygen molecules are continuously removed from the system through the work done by the vacuum pumps, thereby driving the dissociation from $\mathrm{Co}_{3} \mathrm{O}_{4}$ to $\mathrm{CoO}$; there is no equilibrium with any gas. For a thermodynamic assessment of the reduction reaction under equilibrium conditions, we refer to the excellent review by Mayer et al. ${ }^{19}$ and to the work of Navrotsky et al. who also incorporated nanosize effects. ${ }^{14}$

In Fig. 5, high-resolution TEM (HRTEM) images of a particle at room temperature and at $350{ }^{\circ} \mathrm{C}$ are shown, revealing details of the phase transformation. In Fig. 5(a), the particle is single crystalline being observed in a [013]-zone axis at room temperature. At $350{ }^{\circ} \mathrm{C}$ (Fig. 5(b) and (c)), multiple smaller areas displaying a different contrast appeared on the particle, which indicates that the particle was no longer single crystalline at this temperature. The inset images show the Fast Fourier Transforms (FFTs) of the corresponding smaller areas. The FFT images in Fig. 5(b) and (c) show that at $350{ }^{\circ} \mathrm{C}$ the central area of this particle is still in the $\mathrm{Co}_{3} \mathrm{O}_{4}$ phase while the surface area has transformed to $\mathrm{CoO}$. The area marked by the green square in Fig. 5(b) displays the $\mathrm{CoO}$ phase while the white area

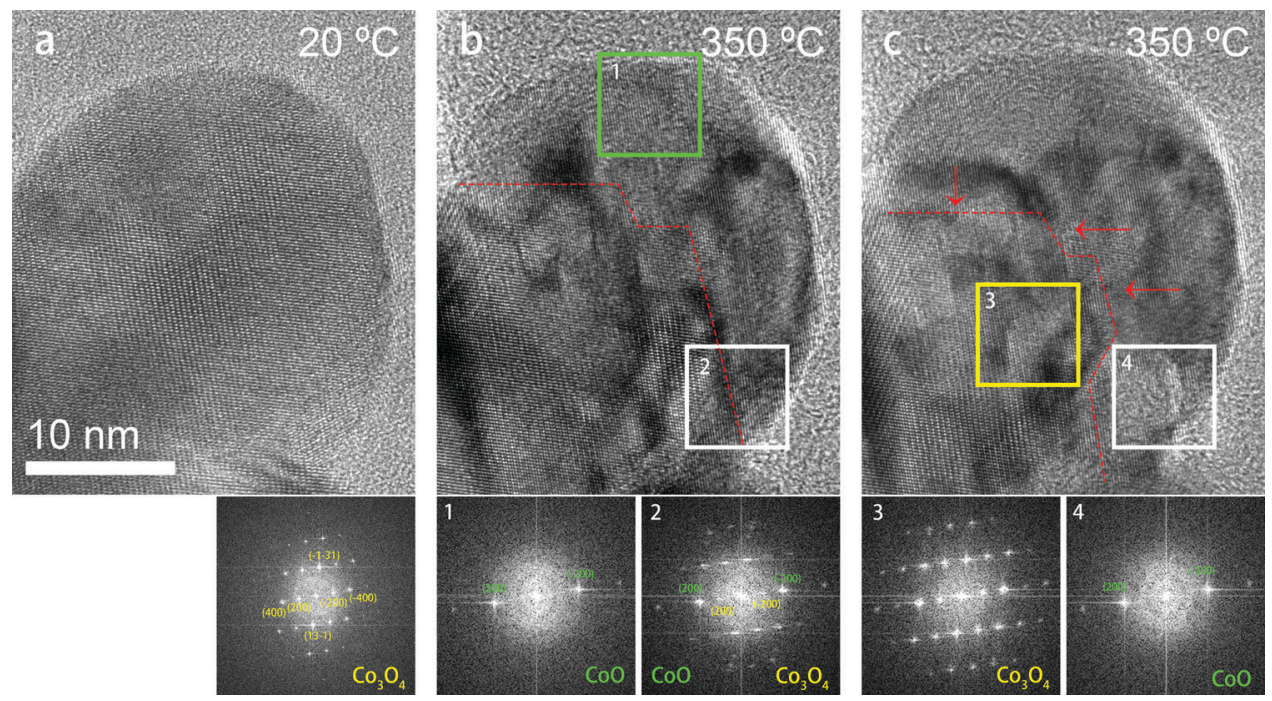

Fig. 5 HRTEM images of a particle imaged in a [013] projection at a temperature of (a) $20^{\circ} \mathrm{C}$; (b) and (c) $350{ }^{\circ} \mathrm{C}$. The image in (c) was taken a few minutes after that in (b). The inset panels are the FFT pattern of the corresponding areas marked in the figure. The spots in the FFT were indexed and show the corresponding lattice planes. The planes written in green belong to the $\mathrm{CoO}$ phase and the yellow ones belong to the $\mathrm{CO}_{3} \mathrm{O}_{4}$ phase. The red dashed lines mark the interfaces between two phases. The $\mathrm{CO}_{3} \mathrm{O}_{4} / \mathrm{CoO}$ interfaces moved inwards from the surface to the center of the nanoparticle. 
contains both $\mathrm{Co}_{3} \mathrm{O}_{4}$ and $\mathrm{CoO}$ phases. However, the white square area transformed to $\mathrm{CoO}$ after a few minutes of continued annealing (shown in Fig. 5(c)), which means that the relative fraction of the $\mathrm{CoO}$ phase increased during heating, while the area marked with the yellow square in Fig. 5(c) was still in the $\mathrm{Co}_{3} \mathrm{O}_{4}$ phase, indicating that the transformation had not proceeded yet into the most central area of the particle. Fig. 5 also shows that at $350{ }^{\circ} \mathrm{C}$ the spots corresponding to the (200) fringes of $\mathrm{CoO}$ are crystallographically aligned with the (400) fringes of $\mathrm{Co}_{3} \mathrm{O}_{4}$. This reveals that during the transformation, there is a cube-on-cube orientation relationship between the $\mathrm{Co}_{3} \mathrm{O}_{4}$ parent nanocrystal and the Co product nanocrystals.

In Fig. 6, aberration-corrected TEM (AC-TEM) images are shown of a particle that had partially transformed to $\mathrm{CoO}$, where the particle is imaged in a [001] projection. The image was taken after swiftly cooling down from $400{ }^{\circ} \mathrm{C}$ to room temperature. Fig. 6(c) and (d) are the FFT patterns indicating a central area (c) that is still in the $\mathrm{Co}_{3} \mathrm{O}_{4}$ phase and an area the edge (d) that has transformed into the CoO phase. The two phases are in a cube-on-cube orientation relationship, in good agreement with the results shown in Fig. 5. Fig. 6(b) shows a magnified HRTEM image of the central area of the particle (marked by the white rectangle in panel (a)), with the $\mathrm{Co}_{3} \mathrm{O}_{4}$ phase at the left hand side and the $\mathrm{CoO}$ phase at the right hand side. Atomic overlays have been drawn to indicate the atomic structures. At the right hand side, the atomic columns match the $\mathrm{CoO}$ structure well. Very distinctively, in the $\mathrm{Co}_{3} \mathrm{O}_{4}$ part of the structure there are additional columns of atoms standing out that are generating a 'diagonal' pattern that is rotated $45^{\circ}$ with respect to the cubic $\mathrm{CoO}$ structure. These atomic columns are the $\mathrm{Co}^{2+}$ ions in $\mathrm{Co}_{3} \mathrm{O}_{4}$. The inset in Fig. 6(b) shows a simulated image of $\mathrm{Co}_{3} \mathrm{O}_{4}$ (using QSTEM, for a thickness of $71.3 \AA$ and a defocus value of $10 \mathrm{~nm}$ ) where this feature is very strong, which confirms the presence of the $\mathrm{Co}_{3} \mathrm{O}_{4}$ structure in the central areas of the partially transformed nanoparticles. Due to changes in thickness, and possibly some mistilt, the contrast of the $\mathrm{Co}_{3} \mathrm{O}_{4}$ part in the images varies to some extent and the interfaces between both phases is not atomically sharp. This may also be caused by the fact that the TEM images are a projection of a 3D structure, while many of these particles display a core-shell structure (with a $\mathrm{Co}_{3} \mathrm{O}_{4}$ core and a $\mathrm{CoO}$ shell), so that in projection the central part is in fact a superposition of both phases including interfaces between them. Both $\{100\} /\{100\}$ and $\{110\} /\{110\}$ interfaces can be distinguished where the transition seems to be gradual. An additional HRTEM image of another particle, showing very similar features, is shown in Fig. S7 of the ESI. $\dagger$

In Fig. 7, HRTEM images of a larger nanoparticle are shown. At room temperature, spots corresponding to $\mathrm{Co}_{3} \mathrm{O}_{4}$ (220)lattice fringes can be clearly observed in the TEM image (panel (a)) and the corresponding FFT pattern (panel (d)). After heating to $400{ }^{\circ} \mathrm{C}$, spots corresponding to (331) lattice fringes appeared, and new pairs of spots also appeared that are very close to the $\mathrm{Co}_{3} \mathrm{O}_{4}(440)$ spots, but which deviate by a small tilt angle and have a slightly smaller $k$-spacing. These pairs of spots correspond to the $\{220\}$ lattice fringes of $\mathrm{CoO}$, which implies that the surface layer of the particle was reduced to $\mathrm{CoO}$, and that this layer is slightly tilted with respect to the $\mathrm{Co}_{3} \mathrm{O}_{4}$ crystal
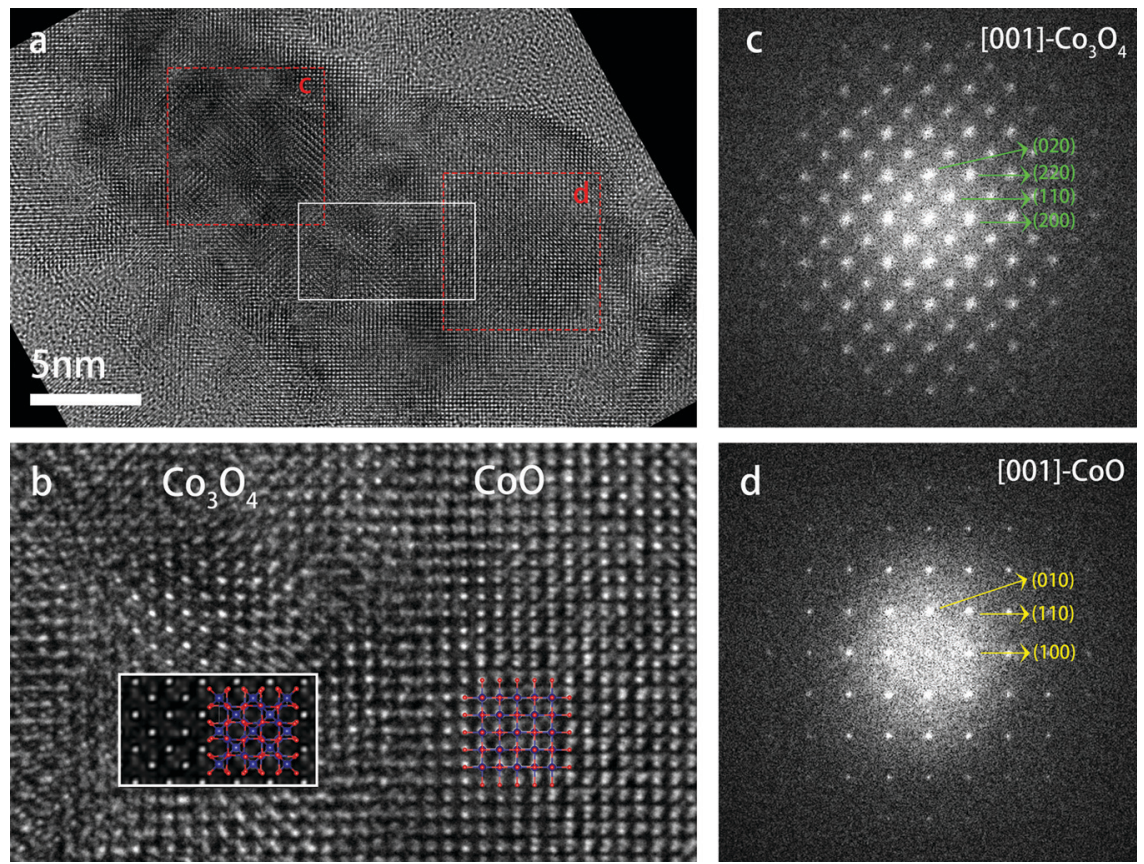

Fig. 6 HRTEM images of a partially transformed particle. (a) Overview of the particle, the exterior and right hand side of the particle is in the CoO phase while the central part is still in the $\mathrm{Co}_{3} \mathrm{O}_{4}$ phase. (b) Magnified image of the area marked by white rectangle in (a). The inset figure is a QSTEM simulated image of $\mathrm{CO}_{3} \mathrm{O}_{4}$. Atomic overlays indicate the $\mathrm{CO}_{3} \mathrm{O}_{4}$ (left) and the $\mathrm{CoO}$ (right) crystal structures. (c) and (d) FFT patterns of the corresponding areas marked in (a), indicating the $\mathrm{CO}_{3} \mathrm{O}_{4}$ and $\mathrm{CoO}$ structures, respectively. 

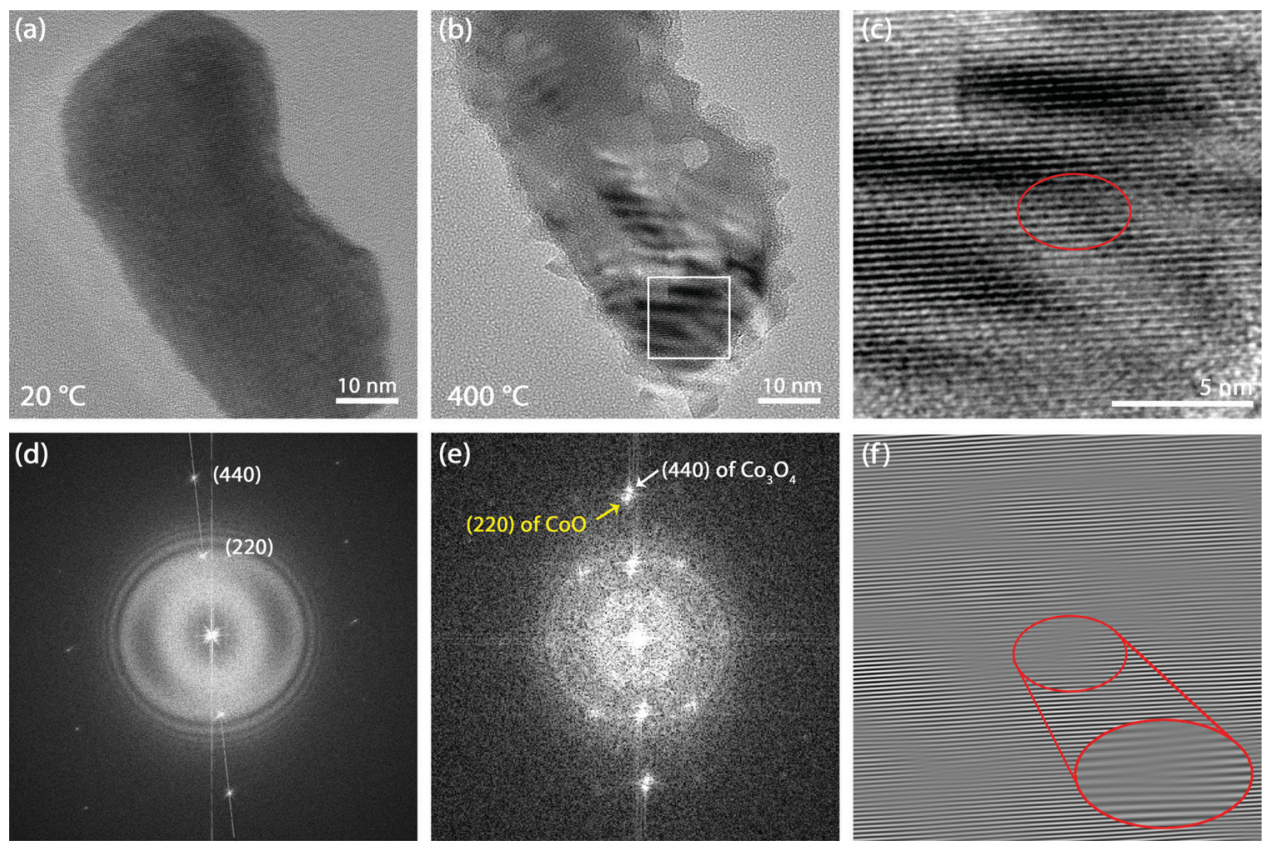

Fig. 7 HRTEM images of a particle at (a) $20^{\circ} \mathrm{C}$ and (b) $400{ }^{\circ} \mathrm{C}$. (c) Magnified image of the area marked in (b); (d) and (e) are the FFTs of (a) and (c), respectively; (f) Inverse FFT image of the (220)-spots in (e). The inset at the bottom-right shows an enlarged view of the dislocation at the center of panel (f).

lattice at the interior of the NP. Similarly small mistilts between the two phases were reported by Ward et al., ${ }^{18}$ who studied the reduction of $\mathrm{Co}_{3} \mathrm{O}_{4}$ nanoparticles in a chemically reducing $\mathrm{H}_{2}$ atmosphere. Combining the result of Fig. 5 and 6, both phases are observed from $350{ }^{\circ} \mathrm{C}$ to $400{ }^{\circ} \mathrm{C}$, which is in good agreement with the result of the DPs. This means that the transformation started from $350{ }^{\circ} \mathrm{C}$ onwards, and progressed inwards from the surface to the center of the particles until complete conversion is achieved at $400{ }^{\circ} \mathrm{C}$.

A moire pattern also appears at the bottom part of the particle, shown in Fig. 7(b), which confirms the multi-layer structure. Fig. 7(f) shows the inverse FFT image of a mask applied around the (220) spots of CoO in Fig. 7(e), showing that dislocations are formed during the reduction. In Fig. 7(b), some voids displaying bright contrast appeared on the particle, which was single crystalline at room temperature before heating. The dislocations and voids are likely formed due to the release of oxygen atoms during the reconstruction of the $\mathrm{Co}_{3} \mathrm{O}_{4}$ structure into the $\mathrm{CoO}$ structure. The dissociation reaction can be written as

$$
\mathrm{Co}_{3} \mathrm{O}_{4} \rightarrow 3 \mathrm{CoO}+\frac{1}{2} \mathrm{O}_{2} .
$$

The oxygen sublattices of $\mathrm{Co}_{3} \mathrm{O}_{4}$ and $\mathrm{CoO}$ are nearly identical, both being fcc sublattices and having a very commensurate lattice parameter (Fig. 1). As $25 \%$ of the $\mathrm{O}$ atoms are released during reduction, the oxygen sublattice and therefore the volume of the nanoparticle itself has to reduce by about $25 \%$ (the positioning and occupation of the Co atoms in the lattices is not limiting their volume). If the shrinkage of the nanoparticle does not proceed fast enough to match the release of oxygen atoms and molecules, the formation of voids and dislocations can be expected.

\section{DFT study of the $\mathrm{CoO} / \mathrm{Co}_{3} \mathrm{O}_{4}$ interface}

Density functional theory (DFT) calculations were conducted on $\mathrm{CoO}$ and $\mathrm{Co}_{3} \mathrm{O}_{4}$ reference bulk phase unit cells and on $\mathrm{CoO} /$ $\mathrm{Co}_{3} \mathrm{O}_{4}$ interface supercells, as described in the Computational details section. To investigate the performance of the DFT (PBE) and $\mathrm{DFT}+U(\mathrm{PBE}+U)$ methods considered in this study in describing the $\mathrm{CoO}$ and $\mathrm{Co}_{3} \mathrm{O}_{4}$ phases, the unit cells of these phases were calculated both with DFT and DFT $+U$. Table 1 summarizes the obtained lattice parameters and band gaps, and the relative energetic stability of the various magnetic geometries. As expected, the Hubbard $U$ correction leads to

Table 1 DFT results for the $\mathrm{CoO}$ and $\mathrm{CO}_{3} \mathrm{O}_{4}$ reference bulk phases. Calculated total energies are given relative to the calculated total energy of the energetically most favorable magnetic ordering for each compound; for this, DFT (PBE) and DFT $+U(\mathrm{PBE}+U)$ are considered separately. The AFM1 and AFM2 orderings of $\mathrm{CO}_{3} \mathrm{O}_{4}$ are identical due to the structure of the $\mathrm{Co}^{2+}$ sublattice. The lattice parameter of $\mathrm{CO}_{3} \mathrm{O}_{4}$ is divided by 2 to allow direct comparison with the lattice parameter of $\mathrm{CoO}$. In the band gap column, ' $M$ ' stands for 'metallic' and 'HM' for 'half-metallic'; the band gap listed for the latter is the band gap found for the spin-up electrons

\begin{tabular}{|c|c|c|c|c|c|c|c|}
\hline \multirow[b]{2}{*}{ Method } & \multirow[b]{2}{*}{ Magnetism } & \multicolumn{2}{|c|}{$\begin{array}{l}\text { Relative energy } \\
\text { (meV per atom) }\end{array}$} & \multicolumn{2}{|c|}{$\begin{array}{l}\text { Lattice } \\
\text { parameter } \\
(\AA) \\
\end{array}$} & \multicolumn{2}{|c|}{ Band gap (eV) } \\
\hline & & $\mathrm{CoO}$ & $\mathrm{Co}_{3} \mathrm{O}_{4}$ & $\mathrm{CoO}$ & $\mathrm{Co}_{3} \mathrm{O}_{4}$ & $\mathrm{CoO}$ & $\mathrm{Co}_{3} \mathrm{O}_{4}$ \\
\hline \multirow[t]{4}{*}{ DFT } & AFM2 & 0 & - & 4.218 & 4.043 & 0.52 & - \\
\hline & AFM1 & 113 & 0 & 4.223 & 4.043 & M & 0.31 \\
\hline & FM & 75 & 4 & 4.247 & 4.046 & HM: 1.08 & 0.16 \\
\hline & NM & 257 & 95 & 4.101 & 4.014 & M & M \\
\hline \multirow[t]{4}{*}{$\mathrm{DFT}+U$} & AFM2 & 345 & - & 4.246 & 4.068 & 1.57 & - \\
\hline & AFM1 & 0 & 0 & 4.295 & 4.068 & 0.91 & 2.14 \\
\hline & FM & 435 & 1 & 4.241 & 4.069 & 2.02 & 2.16 \\
\hline & NM & 857 & 481 & 4.088 & 4.009 & M & M \\
\hline
\end{tabular}


increased band gap values, and even opened up band gaps for the AFM1 and FM CoO configurations, making these configurations no longer metallic and half-metallic as predicted by PBE but semiconducting instead. Surprisingly, it was found that $\mathrm{DFT}+U$ incorrectly predicts the magnetic ground state (MGS) of CoO to be AFM1 rather than AFM2. The deviation of our results from earlier $\mathrm{DFT}+U$ findings in this regard may be related to the higher (and presumably more accurate) energy cutoff used in this work, and to the fact that we performed our calculations on conventional unit cells rather than on the primitive cells. Standard DFT did predict AFM2 to be the lowest-energy phase of $\mathrm{CoO}$, in agreement with experiment. Both DFT and DFT $+U$ correctly predict the MGS of $\mathrm{Co}_{3} \mathrm{O}_{4}$ to be AFM1, although in these cases the ferromagnetic (FM) solution was found to be only slightly less favorable than AFM1. In a combined theoretical and experimental study by Qiao et al., who investigated the electronic structure of $\mathrm{Co}_{3} \mathrm{O}_{4}$ with DFT calculations for a range of $U_{\text {eff }}$ parameters for both $\mathrm{Co}^{2+}$ and $\mathrm{Co}^{3+}$ ions, it was shown that $\mathrm{DFT}+U$ leads to a severe distortion of the top of the valence band in $\mathrm{Co}_{3} \mathrm{O}_{4}$ due to strong downward bending of the band edge corresponding to $\mathrm{Co}^{3+} 3 \mathrm{~d}$ orbitals, ${ }^{25}$ which makes a sensible prediction of the electronic band gap cumbersome. The authors of that study found from their experiments that the fundamental band gap of $\mathrm{Co}_{3} \mathrm{O}_{4}$ is substantially lower $(0.74 \mathrm{eV})$ than typically reported $(1.5-2.5 \mathrm{eV})$, and concluded from their DFT calculations that standard GGAPBE without $U$ correction is best capable of describing the electronic structure of $\mathrm{Co}_{3} \mathrm{O}_{4} \cdot{ }^{25}$

In the present work we are particularly interested in a sufficiently reliable calculation of the total energies for calculating the interface energy between the two phases, and a reliable prediction of the magnetism at the interface. Considering the misidentification of the magnetic ground state for $\mathrm{CoO}$ and the distortion of the valence band of $\mathrm{Co}_{3} \mathrm{O}_{4}$ when using $\mathrm{DFT}+U$, there are no good reasons to choose $\mathrm{DFT}+U$ for the present study, and we performed the interface calculations using standard DFT only. For the (lowest-energy) AFM2 $\mathrm{CoO}$ and AFM1 $\mathrm{Co}_{3} \mathrm{O}_{4}$ phases, Table 2 summarizes the electric charges and magnetic moments on the $\mathrm{Co}^{2+}, \mathrm{Co}^{3+}$, and $\mathrm{O}^{2-}$ atoms, as obtained from standard DFT and Bader volume analysis. Values obtained for the magnetic moments are $\pm 2.30 \mu_{\mathrm{B}}$ for the $\mathrm{Co}^{2+}$ ions in $\mathrm{Co}_{3} \mathrm{O}_{4}$ and $\pm 2.42 \mu_{\mathrm{B}}$ for the $\mathrm{Co}^{2+}$ ions in $\mathrm{CoO}$, in agreement with previously reported values in the literature. ${ }^{22,24}$

Table 2 Calculated properties for the lowest-energy phases of $\mathrm{CoO}$ and $\mathrm{CO}_{3} \mathrm{O}_{4}$ (using GGA-PBE): magnetic ground state (MGS), lattice parameter $a_{0}$ (the lattice parameter of $\mathrm{CO}_{3} \mathrm{O}_{4}$ is divided by 2 to allow direct comparison with the lattice parameter of $\mathrm{CoO}$ ), net magnetic moment $M$ per unit cell, and Bader volume evaluated atomic electric charge $q$ and magnetic moment $m$

\begin{tabular}{|c|c|c|c|c|c|c|c|c|c|}
\hline & \multirow[b]{2}{*}{$a_{0}(\AA)$} & \multicolumn{5}{|c|}{$q(e)$} & \multicolumn{3}{|l|}{$\underline{m\left(\mu_{\mathrm{B}}\right)}$} \\
\hline & & MGS & $M\left(\mu_{\mathrm{B}}\right)$ & $\mathrm{Co}^{2+}$ & $\mathrm{Co}^{3+}$ & $\mathrm{O}^{2-}$ & $\mathrm{Co}^{2+}$ & $\mathrm{Co}^{3+}$ & $\mathrm{O}^{2-}$ \\
\hline $\mathrm{CoO}$ & 4.218 & AFM2 & 0.000 & +1.31 & - & -1.31 & \pm 2.42 & - & 0.00 \\
\hline $\mathrm{Co}_{3} \mathrm{O}_{4}$ & 4.043 & AFM1 & 0.000 & +1.33 & +1.44 & -1.05 & \pm 2.30 & 0.00 & \pm 0.07 \\
\hline
\end{tabular}

Next, the four interface supercells with the magnetic ordering shown in Fig. 2 were fully relaxed. The interface energy of the various interfaces was calculated according to eqn (2) and using the energetically most favorable (AFM2) CoO and (AFM1) $\mathrm{Co}_{3} \mathrm{O}_{4}$ phases as obtained from the bulk phase unit cell calculations as reference phases. Table 3 provides the calculated interface energies and the net magnetic moments of the supercells. The precise supercell dimensions of the obtained output configurations are provided in Table S1 of the ESI. $\dagger$

The atomic output configurations are shown in Fig. 8 and in Fig. S8 of the ESI. $\dagger$ The atomic models are overlaid with isosurfaces of the spin-polarization density, where yellow represents excess spin-up electron density and blue represents excess spin-down electron density. Graphs with an analysis of the Bader evaluated electric charges and magnetic moments on the atoms in the interface supercells are included as well. In Fig. 8(a), the first notable observation is that the magnetic ordering of the AFM2/AFM1 supercell at both sides of the interface is distorted. The (bottom) $\mathrm{CoO}$ slab of the supercell indeed displays an AFM2 ordering, and the (top) $\mathrm{Co}_{3} \mathrm{O}_{4}$ slab an AFM1 ordering; there are, however, clearly a number of $\mathrm{Co}^{2+}$ atoms whose magnetic moment changed sign during relaxation (excess spin-up electron density becoming excess spin-down electron density for these atoms, and vice versa), as indicated with black circles in Fig. 8(a). This can easily be seen by comparing with the input magnetic ordering displayed in Fig. 2( $\mathrm{d}$ and e). Remarkably, these atoms with flipped magnetic moments are found not only close to the interface, but also quite far away (at distances of up to 4 atomic layers) from the interface.

As can be seen from Table 3, the AFM2/AFM1 ordered input configuration resulted in the energetically most favorable interface configuration; i.e., the two bulk components forming the interface, preferably follow the same magnetic ordering as the separate bulk phases. In absolute terms, the interface energy of $0.38 \mathrm{~J} \mathrm{~m}^{-2}$ is quite favorable, in particular considering the $4.2 \%$ lattice mismatch. The NM/NM interface, with the highest total energy and an interface energy of $3.82 \mathrm{~J} \mathrm{~m}^{-2}$, is clearly unfavorable, despite the lower lattice mismatch of $2.1 \%$; the higher energy difference is caused by the fact that here the structure is forced to be nonmagnetic while magnetic solutions are

Table 3 Results of the DFT calculations conducted on the $\{100\} /\{100\}$ $\mathrm{CoO} / \mathrm{CO}_{3} \mathrm{O}_{4}$ interface. The interface designation refers to the various magnetic and nonmagnetic input configurations depicted in Fig. 2. For each interface, the total energy $E_{0}$ with respect to the energy of the lowest-energy supercell, the calculated interfacial area $A_{\text {int, }}$ the surface energy $\gamma_{\text {int }}$ according to eqn (2), and the total net magnetic moment $M$ of the supercell, are given. The lattice mismatch refers to the mismatch between the commensurate lattice parameters of the two separate bulk phases (Table 1) in the plane of the interface. All interface supercells contain the same number of atoms

\begin{tabular}{lllllll}
\hline $\begin{array}{l}\text { Interface } \\
\mathrm{CoO} / \mathrm{Co}_{3} \mathrm{O}_{4}\end{array}$ & $E_{0}(\mathrm{eV})$ & $\begin{array}{l}A_{\text {int }}\left(\AA^{2}\right) \\
\left(\mathrm{eV} \mathrm{\AA}^{-2}\right)\end{array}$ & $\begin{array}{l}\gamma_{\text {int }}\left(\mathrm{J} \mathrm{m}^{-2}\right) \\
\left(\mu_{\mathrm{B}}\right)\end{array}$ & $\begin{array}{l}M \\
(\mathrm{nismatch}(\%)\end{array}$ \\
\hline AFM2/AFM1 & 0.00 & 67.84 & 0.024 & 0.38 & 18.9 & 4.2 \\
$\mathrm{AFM} 1 / \mathrm{AFM} 1$ & 3.11 & 63.58 & 0.050 & 0.80 & 6.5 & 4.4 \\
$\mathrm{FM} / \mathrm{FM}$ & 2.76 & 63.87 & 0.047 & 0.75 & 158.9 & 4.8 \\
$\mathrm{NM} / \mathrm{NM}$ & 26.70 & 62.78 & 0.239 & 3.82 & 0.0 & 2.1
\end{tabular}




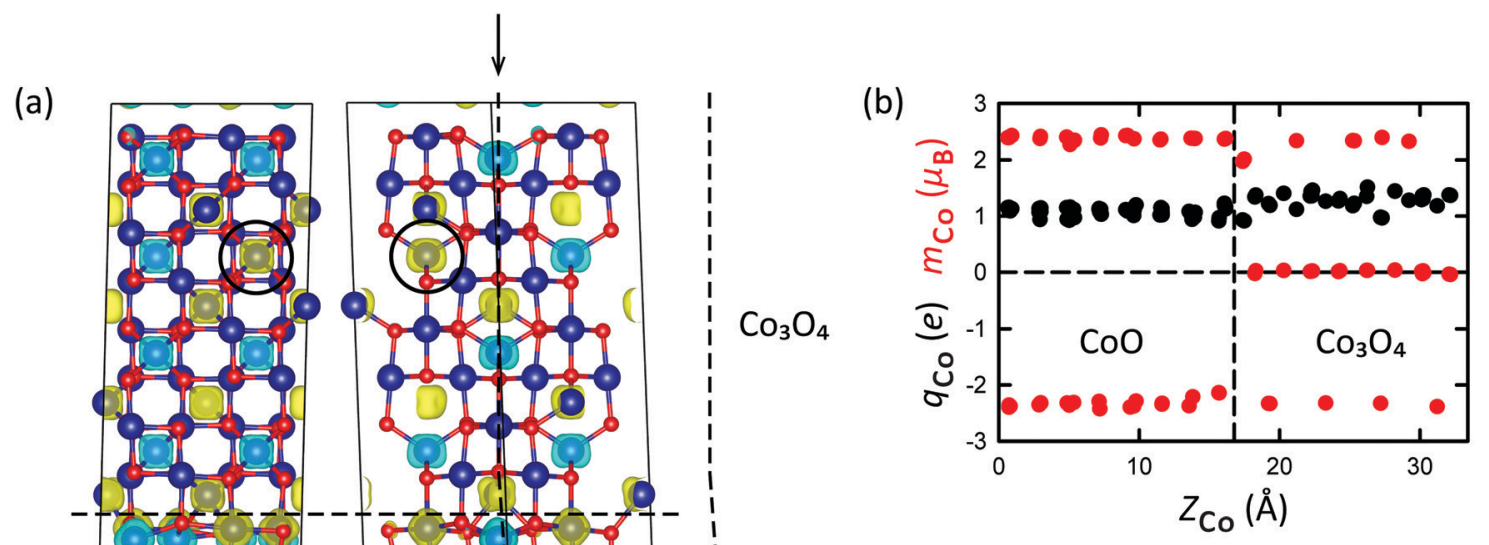

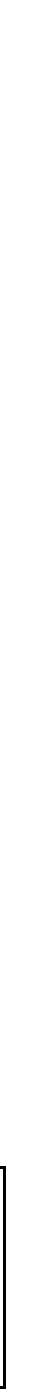

preferred. Fig. 8(a) shows the atomic output configuration for the (lowest-energy) AFM2/AFM1 interface supercell. The output configurations of all interface supercells can be found in Fig. S8 of the ESI. $\dagger$ The charges and magnetic moments on the Co atoms in the relaxed AFM2/AFM1 supercell are shown in Fig. $8(\mathrm{~b})$, where they are plotted as a function of the Z-coordinate (height in the supercell). Fig. S8(d) (ESI $\dagger$ ) includes the charges and magnetic moments on the $\mathrm{O}$ atoms. The correlation between the charges on the atoms and their magnetic moments is nicely visualized in Fig. 8(c). Clearly, the $\mathrm{CoO}$ phase only contains $\mathrm{Co}^{2+}$ ions with either positive or negative magnetic moments, whereas the $\mathrm{Co}_{3} \mathrm{O}_{4}$ phase also contains nonmagnetic $\mathrm{Co}^{3+}$ ions (Fig. 8(b)). The charges and the magnetic moments on the atoms in the supercell in general follow the same trend as the charges and magnetic moments obtained for the atoms in the $\mathrm{CoO}$ and $\mathrm{Co}_{3} \mathrm{O}_{4}$ bulk phase compounds (Table 2). As can be seen from Fig. $8(\mathrm{c})$, the nonmagnetic $\mathrm{Co}^{3+}$ ions have a somewhat higher positive charge of $+1.38 e$ in comparison with the $\mathrm{Co}^{2+}$ ions, which carry an (either spin-up or spin-down) magnetic moment of $\pm 2.34 \mu_{\mathrm{B}}$ and have Bader charges of $+1.09 e$ (all averaged values; the $\mathrm{Co}^{2+}$ atoms with upward magnetic moments actually have an averaged magnetic moment that is slightly larger, namely $+2.37 \mu_{\mathrm{B}}$, than the corresponding value for the magnetically downwardly orientated $\mathrm{Co}^{2+}$ atoms, which was found to be $-2.31 \mu_{\mathrm{B}}$ on average). There is one Co layer (the Co layer closest to the interface at $Z_{\text {rel }} \approx 1 / 2$, in the $\mathrm{Co}_{3} \mathrm{O}_{4}$ component of the supercell) where the $\mathrm{Co}^{2+}$ ions have slightly smaller magnetic moments and Bader charges of $+1.99 \mu_{\mathrm{B}}$ and $+0.92 e$. For the $\mathrm{Co}^{2+}$ atoms of which the magnetic moment changed sign during relaxation, slightly larger values of the magnetic moment were found, of $+2.42 \mu_{\mathrm{B}}$ on average, at Bader charges of $+1.05 e$.

The constituting bulk phases of the AFM2/AFM1 supercell are both AFM-type with zero net magnetic moment (Table 2). Remarkably, the formation of the interface leads to a substantial net ferromagnetic moment of $18.9 \mu_{\mathrm{B}}$ over the entire AFM2/ AFM1 supercell (Table 3). The supercell as a whole is therefore ferrimagnetic. The net ferromagnetic moment that arises from the formation of the interface between the two antiferromagnetic compounds can for the largest part be retraced to the flipping of magnetic moments of $\mathrm{Co}^{2+}$ atoms at both sides of the interface. In total 9 ions changed the sign of their magnetic moment, 6 upwardly and 3 downwardly: in the (bottom) $\mathrm{CoO}$ slab, $3 \mathrm{Co}^{2+}$ ions changed the sign of their magnetic moment from up to down, and 5 changed their sign from down to up; and in the (top) $\mathrm{Co}_{3} \mathrm{O}_{4}$ slab, one $\mathrm{Co}^{2+}$ ion changed its sign from down to up. The 
resulting net contribution of these atoms to the magnetization of the supercell amounts to the equivalence of 3 of their upwardly orientated atomic magnetic moments, and is accompanied by a net contribution of an equal number of (unflipped) atomic magnetic moments from the $\mathrm{Co}^{2+}$ sublattice, where the upwardly orientated magnetic moments of three $\mathrm{Co}^{2+}$ atoms due to the flipping are now no longer matched and counterbalanced by originally downwardly orientated but now flipped magnetic moments. The contribution to the net magnetic moment of the entire supercell due to the flipping of magnetic moments can therefore be estimated to be $3 \times(2.42+2.37)=14.4 \mu_{\mathrm{B}}$. A smaller part $\left(2.0 \mu_{\mathrm{B}}\right)$ of the magnetization of the supercell is caused by the difference in magnetic moment between the spin-up and spindown $\mathrm{Co}^{2+}$ atoms. Note that the two $\mathrm{Co}^{2+}$ atoms at the interface with the smaller magnetic moments will lower the magnetization (their contribution to the net magnetization of the supercell is $\left.-0.6 \mu_{\mathrm{B}}\right)$. The remainder of the supercell magnetization stems from low levels of spin-polarization at the nonmagnetic $\mathrm{O}^{2-}$ and $\mathrm{Co}^{3+}$ atoms, which were found to have very small atomic magnetic moments after relaxation (of $\pm 0.08 \mu_{\mathrm{B}}$ and $\pm 0.03 \mu_{\mathrm{B}}$ on average and adding up to a net contribution of $2.7 \mu_{\mathrm{B}}$ and $0.4 \mu_{\mathrm{B}}$, respectively). Magnetic moments can change sign as a result of the exchange interaction between magnetic moments. In the present case, apparently the broken symmetry and disorder induced by the presence of the interface causes individual magnetic moments at the interface to change in sign, which consecutively causes the adjacent magnetic moment to change in sign as well, eventually leading to flipped magnetic moments quite far away from the interface.

By analogy with the definition of the interface energy (eqn (2)), the net ferromagnetization of the supercell can be expressed per unit of interfacial area as $13.9 \mu_{\mathrm{B}} \mathrm{nm}^{-2}$; the larger part of the magnetization, to a value of $10.3 \mu_{\mathrm{B}} \mathrm{nm}^{-2}$, occurs in the constituting $\mathrm{CoO}$ component, whereas a magnetization of $3.6 \mu_{\mathrm{B}} \mathrm{nm}^{-2}$ was found for the $\mathrm{Co}_{3} \mathrm{O}_{4}$ slab. In the literature, net ferromagnetism in antiferromagnetic nanoparticles was experimentally observed to persist even at room temperature for compounds having a bulk Néel temperature below room temperature, which has generally been attributed to surface and interface effects. ${ }^{32-36}$ The present calculations predict that this is indeed also the case for the $\mathrm{CoO} / \mathrm{Co}_{3} \mathrm{O}_{4}\{100\} /\{100\}$ interface geometry investigated here. We suggest that a follow-up study could study experimentally whether partially converted composite $\mathrm{Co}_{3} \mathrm{O}_{4} / \mathrm{CoO}$ nanoparticles exhibit stronger ferromagnetism than pure $\mathrm{Co}_{3} \mathrm{O}_{4}$ NPs or pure CoO NPs.

The second notable observation that can be made from Fig. 8(a) is that the relaxed AFM2/AFM1 supercell is clearly skewed, most likely under the influence of the directionality along $\langle 111\rangle$ of the antiferromagnetic ordering in the $\mathrm{CoO}$ phase. Please note that when both phases are nonmagnetic (NM/NM), skewing of the supercell does not occur as can been seen in Fig. S8(a) of the ESI. $\dagger$ (The precise dimensions of the supercells can be found in Table S1, ESI. $\dagger$ ) As is indicated by arrows and illustrated schematically at the right-hand side of Fig. 8(a), relaxation resulted in a mistilt of approximately $4^{\circ}$ between the $Z$-axes of the two cubic phases. We point out that a lattice mistilt between the two phases was sometimes also observed in the experiments, as evidenced by the electron diffraction pattern of Fig. 7(e), and by the study by Ward et al. who reduced $\mathrm{Co}_{3} \mathrm{O}_{4}$ in an $\mathrm{H}_{2}$ atmosphere. In theory, the experimentally observed mistilt could be explained from the magnetic interactions between the two phases. As explained in the Introduction, magnetism is often found for nanoparticles above the Curie or Néel temperature of their corresponding bulk phases because of size effects and surface and interface effects. ${ }^{29}$ In addition, there is quite a strong magnetic field present in the electron microscope with field strengths up to 2 Tesla, ${ }^{47}$ which can easily induce magnetization. Nonetheless, we consider that, whereas the skewing and mistilt observed in the simulations are most likely related to the different directionality of the magnetic ordering of the two phases, the most plausible explanation for the experimentally observed lattice mistilt is the formation of dislocations in the oxygen sublattice, as revealed by the real-space HRTEM observations.

\section{Conclusion}

The thermal reduction process of $\mathrm{Co}_{3} \mathrm{O}_{4}$ nanoparticles to $\mathrm{CoO}$ was investigated by in situ heating in the TEM under vacuum conditions. The results show that transformation of the $\mathrm{Co}_{3} \mathrm{O}_{4}$ NPs starts at $350{ }^{\circ} \mathrm{C}$ and that the NPs are completely converted after heating at $400{ }^{\circ} \mathrm{C}$ for $10 \mathrm{~min}$. Upon heating to higher temperatures, up to $900{ }^{\circ} \mathrm{C}$, no further reduction was observed. The reaction proceeds from the surface to the center of the particle, where the parent $\mathrm{Co}_{3} \mathrm{O}_{4}$ and the product $\mathrm{CoO}$ nanoparticles are in a cube-on-cube orientation relationship of their crystal lattices. The $\mathrm{CoO}$ reduced surface layer was sometimes slightly tilted with respect to the $\mathrm{Co}_{3} \mathrm{O}_{4}$ interior, which is likely associated with the formation of dislocations as the volume of the NPs has to reduce by $25 \%$ due to oxygen release. The transformation did not take place during ex situ heating experiments conducted in air and under nitrogen flow, however the transformation was achieved $e x$ situ when heating in a high vacuum chamber; vacuum conditions, equivalent to a very low partial oxygen pressure, are necessary for achieving the transformation to $\mathrm{CoO}$ at a temperature of $400{ }^{\circ} \mathrm{C}$.

The energetics and magnetic structure of the interface were investigated by density functional theory (DFT) calculations predicting a favorable $\mathrm{CoO} / \mathrm{Co}_{3} \mathrm{O}_{4}\{100\} /\{100\}$ interface energy of $0.38 \mathrm{~J} \mathrm{~m}^{-2}$. The antiferromagnetic orderings of the two phases at both sides of the interface, AFM2 for $\mathrm{CoO}$ and AFM1 for $\mathrm{Co}_{3} \mathrm{O}_{4}$, correspond to those of the lowest-energy bulk phases. It was also found, however, that the magnetic ordering is distorted as several atoms have magnetic moments with a sign that is opposite to the sign that would yield the perfect magnetic order. The distortion in the antiferromagnetic ordering takes place at the interface but also leads to flipping of magnetic moments at a considerable distance $(\sim 1 \mathrm{~nm})$ from the interface, likely due to exchange coupling. The flipping in sign of the magnetic moments leads to a considerable net ferromagnetic moment of $18.9 \mu_{\mathrm{B}}$ over the entire supercell, which corresponds 
to a net magnetization of approximately $13.9 \mu_{\mathrm{B}} \mathrm{nm}^{-2}$. We suggest that verifying experimentally whether the presence of the $\mathrm{Co}_{3} \mathrm{O}_{4} / \mathrm{CoO}$ interface indeed enhances the ferromagnetism of NPs with respect to pure $\mathrm{Co}_{3} \mathrm{O}_{4}$ or pure $\mathrm{CoO}$ NPs, would be an interesting topic for an experimental follow-up study. Both in the experiments and in the simulations, a small mistilt between the two cubic phases was found. In the simulations, this is likely related to stress fields originating from different directionalities of the antiferromagnetic orderings in $\mathrm{CoO}$ and $\mathrm{Co}_{3} \mathrm{O}_{4}$. In the experiments, this is likely due to the formation of dislocations in the oxygen sublattice during the thermal reduction. In the present work we show that the formation of an interface leads to ferromagnetism in otherwise only antiferromagnetic materials. Although we demonstrate this solely for the $\mathrm{Co}_{3} \mathrm{O}_{4} / \mathrm{CoO}$ interface, this effect can be expected to take place in many other transition metal oxide systems as well. The implication of the current findings is that it could be very beneficial to reduce transition metal oxide nanoparticles only partially, in order to boost ferromagnetism at their interfaces. This would be an interesting topic for an experimental followup study, as generating ferromagnetism simply by partial reduction would make these nanoparticles interesting to a much wider range of applications including magnetic recording media, sensing, and biomedical applications. ${ }^{48-50}$

\section{Author contributions}

MAvH conceived the experimental part of the study. XDC performed and analyzed the in situ and ex situ heating experiments. HvG conceived the computational part of the study and performed and analyzed the DFT calculations. XDC and HvG wrote the manuscript. All authors commented on the manuscript.

\section{Conflicts of interest}

There are no conflicts to declare.

\section{Acknowledgements}

MAvH acknowledges funding by the European Research Council through an ERC Consolidator Grant (Grant No. 683076). Part of this work was carried out on the Dutch national e-infrastructure with the support of SURF Cooperative. Figures of atomic structural models and spin-polarization density plots were produced using VESTA. ${ }^{51}$ We thank Bo van den Bosch, who participated in the experiments within the framework of the 'Research Traineeship' 2nd year Bachelor course at Utrecht University. We thank Albert Grau Carbonell and Hans Meeldijk for EM support, and Profs. Alfons van Blaaderen and Petra de Jongh for useful discussions.

\section{References}

1 R. Zhang, Y. C. Zhang, L. Pan, G.-Q. Shen, N. Mahmood, Y.-H. Ma, Y. Shi, W. Jia, L. Wang, X. Zhang, W. Xu and J.-J. Zou, ACS Catal., 2018, 8, 3803.

2 F. Song, L. Bai, A. Moysiadou, S. Lee, C. Hu, L. Liardet and X. Hu, J. Am. Chem. Soc., 2018, 140, 7748.

3 B. Ernst, A. Bensaddik, L. Hilaire, P. Chaumette and A. Kiennemann, Catal. Today, 1998, 39, 329.

4 L. J. Garces, B. Hincapie, R. Zerger and S. L. Suib, J. Phys. Chem. C, 2015, 119, 5484.

5 P. A. Connor and J. T. S. Irvine, Electrochim. Acta, 2002, 47, 2885.

6 D. Su, S. Dou and G. Wang, Sci. Rep., 2014, 4, 5767.

7 W. Y. Li, L. N. Xu and J. Chen, Adv. Funct. Mater., 2005, 15, 851.

8 R. Dehghan, T. W. Hansen, J. B. Wagner, A. Holmen, E. Rytter, Ø. Borg and J. C. Walmsley, Catal. Lett., 2011, 141, 754.

9 O. A. Bulavchenko, S. V. Cherepanova, V. V. Malakhov, L. S. Dovlitova, A. V. Ishchenko and S. V. Tsybulya, Kinet. Catal., 2009, 50, 192.

10 D. Potoczna-Petru and L. Kępiński, Catal. Lett., 2001, 73, 41.

11 O. Kitakami, H. Sato, Y. Shimada, F. Sato and M. Tanaka, Phys. Rev. B: Condens. Matter Mater. Phys., 1997, 56, 13849.

12 M. Chen, B. Hallstedt and L. J. Guackler, J. Phase Equilibr., 2003, 24, 212.

13 F.-C. Kong, Y.-F. Li, C. Shang and Z.-P. Liu, J. Phys. Chem. C, 2019, 123, 17539.

14 A. Navrotsky, C. Ma, K. Lilova and N. Birkner, Science, 2010, 330, 199.

15 B. Tomić-Tucaković, D. Majstorović, D. Jelić and S. Mentus, Thermochim. Acta, 2012, 541, 15.

16 G. Ji, S. Smart, S. K. Bhatia and J. C. Diniz da Costa, Sep. Purif. Technol., 2015, 154, 338.

17 K. C. Sabat, R. K. Paramguru, S. Pradhan and B. K. Mishra, Plasma Chem. Plasma Process., 2015, 35, 387.

18 M. R. Ward, E. D. Boyes and P. L. Gai, ChemCatChem, 2013, 5, 2655.

19 N. A. Mayer, D. M. Cupid, R. Adam, A. Reif, D. Rafaja and H. J. Seifert, Thermochim. Acta, 2017, 652, 109.

20 M. A. van Huis, N. P. Young, G. Pandraud, J. F. Creemer, D. Vanmaekelbergh, A. I. Kirkland and H. W. Zandbergen, Adv. Mater., 2009, 21, 4992.

21 T. Archer, R. Hanafin and S. Sanvito, Phys. Rev. B: Condens. Matter Mater. Phys., 2008, 78, 014431.

22 H.-X. Deng, J. Li, S.-S. Li, J.-B. Xia, A. Walsh and S.-H. Wei, Appl. Phys. Lett., 2010, 96, 162508.

23 A.-L. Dalverny, J.-S. Filhol, F. Lemoigno and M.-L. Doublet, J. Phys. Chem. C, 2010, 114, 21750.

24 J. Chen, X. Wu and A. Selloni, Phys. Rev. B: Condens. Matter Mater. Phys., 2011, 83, 245204.

25 L. Qiao, H. Y. Xiao, H. M. Meyer, J. N. Sun, C. M. Rouleau, A. A. Puretzky, D. B. Geohegan, I. N. Ivanov, M. Yoon, W. J. Weber and M. D. Biegalski, J. Mater. Chem. C, 2013, 1, 4628 . 
26 F. B. Lewis and N. H. Saunders, J. Phys. C: Solid State Phys., 1973, 6, 2525.

27 E. Z. Kurmaev, R. G. Wilks, A. Moewes, L. D. Finkelstein, S. N. Shamin and J. Kunes, Phys. Rev. B: Condens. Matter Mater. Phys., 2008, 77, 165127.

28 V. R. Shinde, S. B. Mahadik, T. P. Gujar and C. D. Lokhande, Appl. Surf. Sci., 2006, 252, 7487.

29 Y. A. Koksharov, in Magnetic Nanoparticles, ed. S. P. Gubin, Wiley, Weinheim, 2009, ch. 6, pp. 197-254.

30 S. Sako, K. Ohshima, M. Sakai and S. Bandow, Surf. Rev. Lett., 1996, 3, 109.

31 L. He, C. Chen, N. Wang, W. Zhou and L. Guo, J. Appl. Phys., 2007, 102, 103911.

32 S. R. Gawali, A. C. Gandhi, S. S. Gaikwad, J. Pant, T.-S. Chan, C.-L. Cheng, Y.-R. Ma and S. Y. Wu, Sci. Rep., 2018, 8, 249.

33 L. Zhang, D. Xue and C. Gao, J. Magn. Magn. Mater., 2003, 267, 111-114.

34 G. Yang, D. Gao, Z. Shi, Z. Zhang, J. Zhang, J. Zhang and D. Xue, J. Phys. Chem. C, 2010, 114, 21989.

35 C. Nethravathi, S. Sen, N. Ravishankar, M. Rajamathi, C. Pietzonka and B. Harbrecht, J. Phys. Chem. B, 2005, 109, 11468.

36 Z.-A. Li, N. Fontaíña-Troitiño, A. Kovács, S. Liébana-Viñas, M. Spasova, R. E. Dunin-Borkowski, M. Müller, D. Doennig, R. Pentcheva, M. Farle and V. Salgeuiriño, Sci. Rep., 2015, 5, 7997.

37 C.-W. Tung, Y.-Y. Hsu, Y.-P. Shen, Y. Zheng, T.-S. Chan, H.-S. Sheu, Y.-C. Cheng and H. M. Chen, Nat. Commun., 2015, 6, 8106.
38 R. F. W. Bader, Atoms in Molecules: A Quantum Theory, Oxford University Press, Oxford, UK, 1990.

39 G. Kresse and J. Furthmüller, Comput. Mater. Sci., 1996, 6, 15. 40 G. Kresse and J. Furthmüller, Phys. Rev. B: Condens. Matter Mater. Phys., 1996, 54, 11169.

41 P. E. Blöchl, Phys. Rev. B: Condens. Matter Mater. Phys., 1994, 50, 17953.

42 G. Kresse and D. Joubert, Phys. Rev. B: Condens. Matter Mater. Phys., 1999, 59, 1758.

43 J. P. Perdew, K. Burke and M. Ernzerhof, Phys. Rev. Lett., 1996, 77, 3865.

44 S. L. Dudarev, G. A. Botton, S. Y. Savrasov, C. J. Humphreys and A. P. Sutton, Phys. Rev. B: Condens. Matter Mater. Phys., 1998, 57, 1505.

45 H. J. Monkhorst and J. D. Pack, Phys. Rev. B: Solid State, 1976, 13, 5188.

46 G. Henkelman, A. Arnaldsson and H. A. Jónsson, Comput. Mater. Sci., 2006, 36, 354.

47 N. Shibata, Y. Kohno, A. Nakamura, S. Morishita, T. Seki, A. Kumamoto, H. Sawada, T. Matsumoto, S. D. Findlay and Y. Ikuhara, Nat. Commun., 2019, 10, 2308.

48 S. Singamaneni, V. N. Bliznyuk, C. Binek and E. Y. Tsymbal, J. Mater. Chem., 2011, 21, 16819.

49 H. Lai, F. Xu and L. Wang, J. Mater. Sci., 2018, 53, 8677.

50 Q. A. Pankhurst, J. Connolly, S. K. Jones and J. Dohson, J. Phys. D: Appl. Phys., 2003, 36, R167.

51 K. Momma and F. Izumi, J. Appl. Crystallogr., 2011, 44, 1272. 